\title{
Correction to: Biotinidase Deficiency Presenting as Recurrent Laryngeal Stridor
}

\author{
Sruthi Alanghat ${ }^{1} \cdot$ John $_{\text {Matthai }}{ }^{2} \cdot$ Vidhya Marimuthu $^{1} \cdot$ R. Manivasakan ${ }^{3} \cdot$ M. Ramaswamy $^{1}$ \\ Published online: 16 April 2021 \\ (C) Dr. K C Chaudhuri Foundation 2021
}

Correction to: The Indian Journal of Pediatrics. https://doi.org/10.1007/s12098-020-03635-y

The image inside Fig. 1a went missing during the typesetting process. The correct Fig. 1 is shown below.

The original article has been corrected.

The online version of the original article can be found at https://doi.org/ $10.1007 /$ s12098-020-03635-y

\footnotetext{
Sruthi Alanghat

sruthialanghat@gmail.com

1 Department of Pediatrics, Masonic Medical Centre for Children, Coimbatore, Tamil Nadu, India

2 Department of Gastroenterology, Masonic Medical Centre for Children, Coimbatore, Tamil Nadu, India

3 Department of Neurology, Masonic Medical Centre for Children, Coimbatore, Tamil Nadu, India
} 


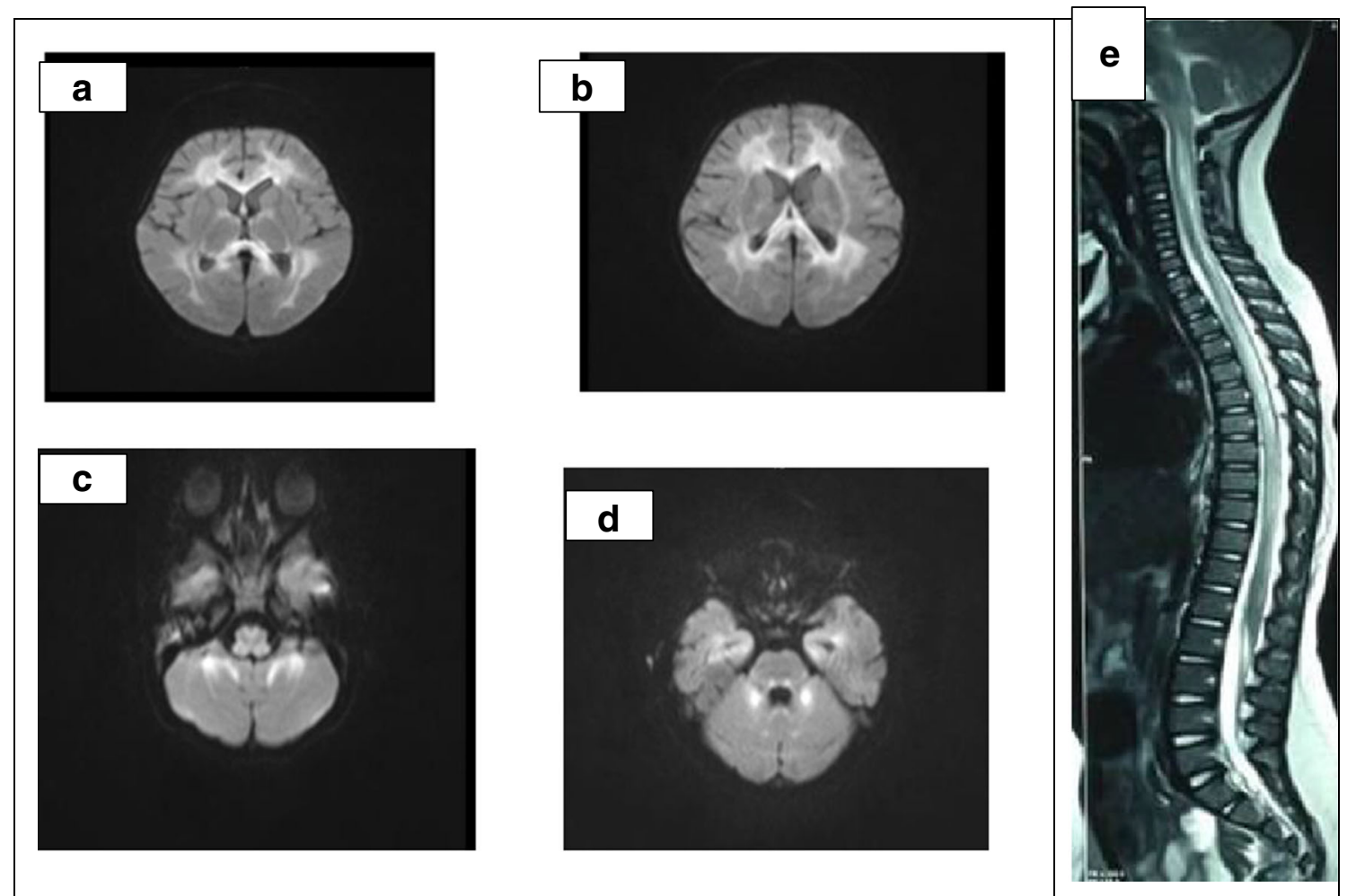

Fig. 1 Magnetic resonance imaging (MRI) of the brain and spinal cord done [Diffusion-weighted imaging (DWI) axial section a-d, T2- weighted image (T2W1) sagittal section e], which showed symmetrical white matter hyperintensities in corpus callosum (a), bilateral cerebral white matter (b), medulla (c), parts of pons (d) with long segment myelopathy of spinal cord from cervicomedullary junction to D10 level (e)

Publisher's Note Springer Nature remains neutral with regard to jurisdictional claims in published maps and institutional affiliations. 